\title{
Preparation of Al-Mg Alloy Electrodes by Using Powder Metallurgy and Their Application for Hydrogen Production
}

\author{
Wen-Nong Hsu, ${ }^{1,2}$ Teng-Shih Shih,, ${ }^{1}$ and Ming-Yuan Lin $^{2}$ \\ ${ }^{1}$ Department of Mechanical Engineering, National Central University, Chung-Li 32054, Taiwan \\ ${ }^{2}$ Department of Mechanical and Vehicle Engineering, Army Academy, Chung-Li 32092, Taiwan \\ Correspondence should be addressed to Wen-Nong Hsu; nong88@yam.com
}

Received 4 August 2014; Accepted 26 August 2014; Published 23 November 2014

Academic Editor: Chin-Chia Wu

Copyright (c) 2014 Wen-Nong Hsu et al. This is an open access article distributed under the Creative Commons Attribution License, which permits unrestricted use, distribution, and reproduction in any medium, provided the original work is properly cited.

\begin{abstract}
The choice of an electrode is the most critical parameter for water electrolysis. In this study, powder metallurgy is used to prepare aluminum-magnesium (Al-Mg) alloy electrodes. In addition to pure $\mathrm{Mg}$ and $\mathrm{Al}$ electrodes, five $\mathrm{Al}-\mathrm{Mg}$ alloy electrodes composed of $\mathrm{Al}-\mathrm{Mg}$ (10 wt\%), Al-Mg (25 wt\%), Al-Mg (50 wt\%), and Al-Mg (75 wt\%) were prepared. In water electrolysis experiments, the pure $\mathrm{Al}$ electrode exhibited optimal electrolytic efficiency. However, the Al-Mg ( $25 \mathrm{wt} \%)$ alloy was the most efficient when the anticorrosion effect and materials costs were considered. In this study, an ultrasonic field was applied to the electrolysis cell to improve its efficiency. The results revealed that the current increased by approximately $23.1 \%$ when placed in a $30 \mathrm{wt} \% \mathrm{KOH}$ solution under the ultrasonic field. Electrochemical polarization impedance spectroscopy (EIS) was employed to evaluate the effect of the ultrasonic field on the reduction of polarization resistance. The results showed that the concentration impedance in the $30 \mathrm{wt} \%$ $\mathrm{KOH}$ electrolyte decreased markedly by $44 \%-51 \% \Omega$.
\end{abstract}

\section{Introduction}

Hydrogen is a clean pollution-free and economical energy carrier, which indicates that it has the greatest potential for use as an alternative energy source. Hydrogen releases energy without producing greenhouse gases, such as $\mathrm{CO}_{2}$, and it has the highest power density among all fuels. It has high development potential, and it is a clean power source with an indefinite supply. In the 1800s, scientists generated high-purity hydrogen and oxygen by conducting water electrolysis. Water contains a large amount of hydrogen, and it is the ideal material to obtain it from. Hydrogen power is superior to other energy sources because it is renewable and can be used to generate electric power or heat. Through a chemical reaction, hydrogen can form water, which can be decomposed into hydrogen and oxygen through electrolysis. Therefore, performing water electrolysis to produce hydrogen is a crucial method for generating energy. Improving the efficiency of water electrolysis for hydrogen production is a valuable research topic.
The voltage required to perform water electrolysis consists of largely reversible potential $\left(1.23 \mathrm{~V}, 1 \mathrm{~atm}, 25^{\circ} \mathrm{C}\right)$. However, the actual decomposition potential is higher than $1.23 \mathrm{~V}$. Low reaction overpotential is crucial to improving the efficiency and economic viability of water hydrolysis, because high energy consumption and a low hydrogen output are two issues affecting the applicability of water electrolysis [1]. To reduce the overpotential and increase the hydrogen output, several previous studies have discussed the effects of working parameters such as alkaline $(\mathrm{KOH}, \mathrm{NaOH})$ or acid $\left(\mathrm{HCl}, \mathrm{H}_{2} \mathrm{SO}_{4}\right)$ electrolytes, relative electrode distance, flowfield effect, and electrolyte temperature on the electrolytic hydrogen production efficiency. For example, Nagai et al. [2], de Souza et al. [3, 4], and Licht et al. [5] have shown that the flow field generated from electrolyte stirring resulted in a higher ion concentration on the electrode surface, thereby increasing the electrolytic efficiency. Dubey et al. [6] employed carbon nanotubes to replace graphite electrodes, to increase the efficiency of hydrogen production. Nikolic et al. [7] added cobalt and tungsten ions to an alkaline 
electrolyte, reduced the power consumption by $15 \%$, and produced the same amount of hydrogen. In addition, certain studies have used additional external mechanisms to improve the efficiency of water electrolysis. For example, Lin et al. [8] applied a magnetic field to an electrolyte solution to discuss the magnetic phenomenon of electrolytes under the Lorentz force and demonstrated improvements in the polarization potential and hydrogen production efficiency. Matsushima et al. $[9,10]$ applied a magnetic field during electrolysis to examine the polarization overpotential curve in oversaturated electrolytes.

In water electrolysis, one of the most critical factors is the choice of an electrode material. The characteristics of an ideal electrode include low operating potential, favorable electrocatalytic properties, time stability, and low cost. Platinum is widely used as an electrode material, although it is relatively expensive. Considering the cost, iron, cobalt, nickel, stainless steel, and graphite are also widely used electrode materials $[11,12]$. Regarding the methods for manufacturing electrodes, powder metallurgy is a convenient and efficient technique that has numerous advantages such as low energy consumption, efficient material usage, and simple procedure. Furthermore, its products can be designed with porosity, uniform chemical composition, refractory materials, and incompatible composite materials. For this study, Al-Mg electrodes of various compositions were sintered, and their electrolytic performance was subsequently evaluated in distinct alkaline electrolytes to identify electrodes suitable for water electrolysis. Finally, we applied an ultrasonic field to accelerate the reduction of the accumulated impedance caused by the formation of numerous bubbles on the electrode surface. Highfrequency longitudinal ultrasonic waves cause continuous changes in positive and negative pressure in fluid media and generate tens of thousands of microvacuum bubbles, a phenomenon known as "cavitation bubbles" [13-16]. Cavitation bubbles continuously form, extrude, and break, resulting in the disturbance and rapid degasification of the fluid. Early in the nineteenth century, metallurgists understood that applying ultrasonic energy to a molten medium would uniformly disperse impurities and have a degassing effect. This could improve the quality of cast products substantially $[16,17]$. This study examined the effect of applying ultrasonic energy to various electrolyte concentrations during water electrolysis and evaluated the effect of various electrodes on the performance of hydrogen production. Electrochemical polarization impedance spectroscopy (EIS) was employed to measure the related polarization phenomena, and a camera was used to capture images of the bubble flow field.

\section{Experimental}

The electrodes used in the study were prepared using a powder metallurgy method. Pure $\mathrm{Al}$ and $\mathrm{Mg}$ powders were used as raw materials. The mean particle size of both powders was approximately 100 mesh. In addition, five alloy electrodes composed of Al-Mg (10 wt\%), Al-Mg (25 wt\%), Al$\mathrm{Mg}$ (50 wt\%), $\mathrm{Al}-\mathrm{Mg}$ (75 wt\%), and $\mathrm{Al}-\mathrm{Mg}(90 \mathrm{wt} \%)$ were also prepared. After thoroughly mixing the various compositions

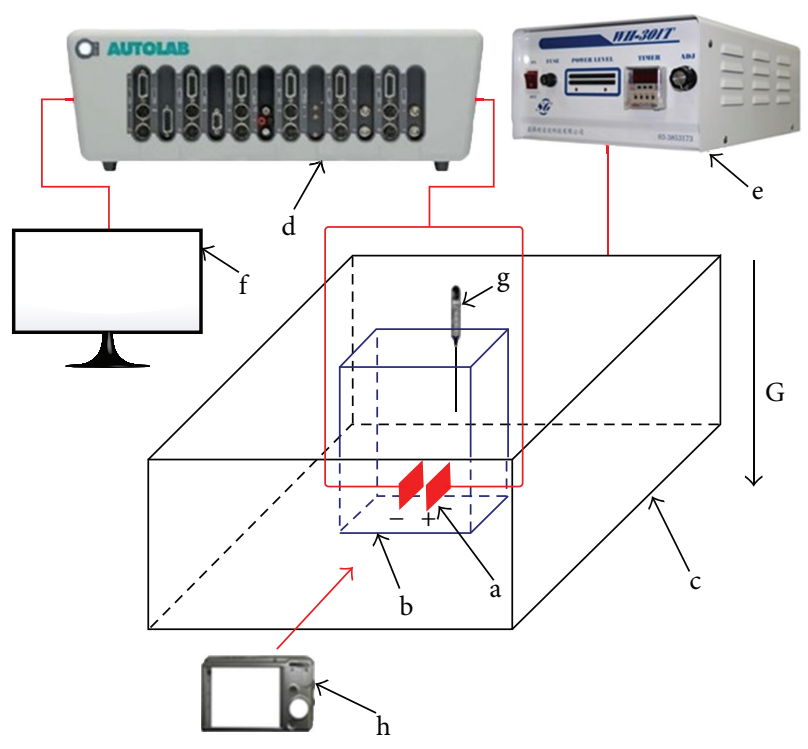

FIgURE 1: The experiment devices. (a) Electrodes, (b) electrolysis cell, (c) outer cell, (d) potentiostat, (e) ultrasonic generator, (f) computer, (g) thermometer, and (h) camera.

of powder, the mixture was placed in a metal mold and pressed at $200 \mathrm{MPa}$ for $30 \mathrm{~s}$. To prevent oxidation at elevated temperatures, a quartz tube furnace was filled with protective gas (hydrogen) during the sintering process. The electrode specimens were sintered to $500^{\circ} \mathrm{C}$, held at that temperature for $3 \mathrm{~h}$, and then left to cool to room temperature in the furnace. The sintered electrode specimens were fabricated with a dimension of $12 \times 12 \times 5 \mathrm{~mm}(L \times W \times H)$ for subsequent analysis.

Because Ni electrodes are corrosion-proof as well as acidand alkali-resistant in electrolytes, a pure $\mathrm{Ni}$ anode was used in this study. Seven types of electrodes were prepared as cathodes (working electrodes), with a total geometric area of approximately $144 \mathrm{~mm}^{2}$. The distance between electrodes was fixed at $30 \mathrm{~mm}$. Three electrolyte concentrations (i.e., $10 \mathrm{wt} \%$, $20 \mathrm{wt} \%$, and $30 \mathrm{wt} \%)$ of $\mathrm{KOH}$ were used. The electrobath used in this experiment was composed of an acid- and alkaliresistant acrylic material $(30 \times 15 \times 100 \mathrm{~mm} ; L \times W \times H)$. Figure 1 shows the experimental apparatus. The AUTOLAB PGSTAT302N potentiostat of the Netherlands ECO was used for the I-V curve measurement of water electrolysis in each electrode to analyze the electrolytic performance. A 225-W ultrasonic field was introduced to the outer cell during water electrolysis. A camera was used to record the effect of the ultrasonic field on the bubble beams. In this experiment, the frequency response analyzer (FRA) module of the potentiostat was used to measure the EIS curves of the electrochemical reaction. The EIS curve was transformed into the impedance spectrum by using the Nyquist curve of the equivalent circuit. Curve fitting was performed using software to analyze the impedance distribution in the setequivalent circuit and to obtain the impedance values. Based on these data, the following section discusses the effects of 
TABLE 1: The electrolytic performance of the experimental electrodes.

\begin{tabular}{|c|c|c|c|c|c|c|c|}
\hline \multirow{2}{*}{ Property } & \multicolumn{7}{|c|}{ Electrodes } \\
\hline & $\mathrm{Mg}$ & $\mathrm{Al}-\mathrm{Mg}(90 \mathrm{wt} \%)$ & Al-Mg (75 wt\%) & Al-Mg (50 wt\%) & $\mathrm{Al}-\mathrm{Mg}(25 \mathrm{wt} \%)$ & $\mathrm{Al}-\mathrm{Mg}(10 \mathrm{wt} \%)$ & $\mathrm{Al}$ \\
\hline (a) Conductivity (IACS) & 38 & 11 & 7 & 4 & 8 & 14 & 62 \\
\hline (b) Corrosion rate (\%) & 0 & 0 & 0 & 0 & 0 & 45 & 99 \\
\hline (c) Decomposition voltage (V) & 3.65 & 3.50 & 3.40 & 3.15 & 2.85 & 2.55 & 2.35 \\
\hline
\end{tabular}

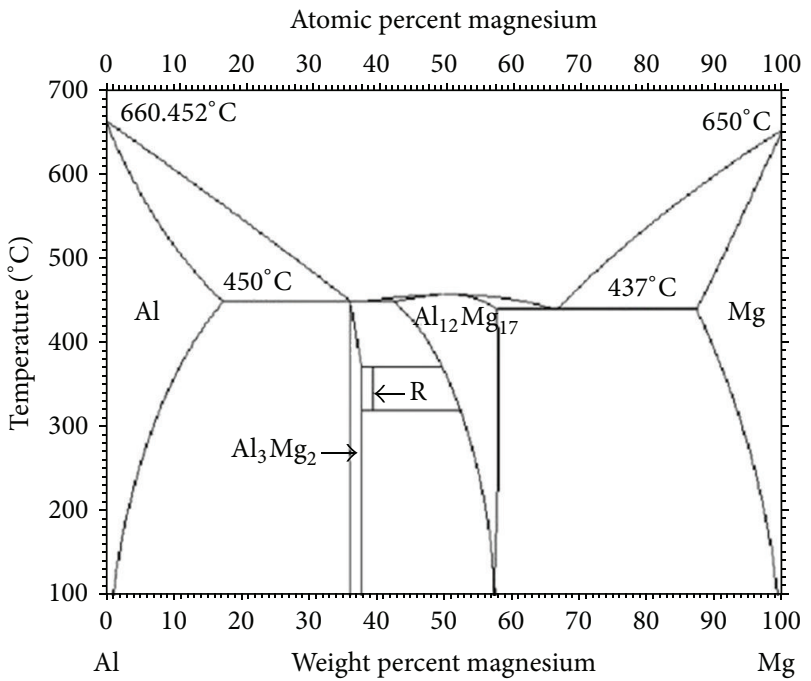

Figure 2: The phase diagram of Al-Mg alloy.

the various parameters on the impedance values during the electrochemical experimental process.

\section{Results and Discussion}

3.1. Electrolytic Performance of the Al-Mg Electrodes. The phase diagram in Figure 2 shows the microstructures of the materials used in this study. Selecting an electrode material first involves considering its electrical conductivity, because a high electrical conductivity facilitates efficient electrolysis. In this study, conductivity is expressed in accordance with the International Annealed Copper Standard (IACS). Table 1 (line A) shows the conductivity results of the electrodes. The pure $\mathrm{Al}$ and $\mathrm{Mg}$ electrodes were more conductive than the alloy composites (62 IACS and 38 IACS, resp.). However, the conductivity of the Al-Mg (50 wt\%) alloy electrodes yielded substantially lower values (4 IACS), exhibiting the lowest conductivity.

Electrode materials should exhibit corrosion resistance to basic electrolytes. Table 1 (line B) shows the relationship between the electrolysis time and corrosion weight percentage for each electrode at a fixed voltage of $5 \mathrm{~V}$ in the $30 \mathrm{wt} \%$ $\mathrm{KOH}$ electrolyte for $8 \mathrm{~h}$. The pure $\mathrm{Al}$ and $\mathrm{Al}-\mathrm{Mg}$ (10 wt\%) electrodes were subject to corrosion. Formula (1) shows the reaction of the pure $\mathrm{Al}$ sample in the $\mathrm{KOH}$ electrolyte. The $\mathrm{KOH}$ electrolyte in water was dissociated to yield $\mathrm{K}^{+}$and $\mathrm{OH}^{-}$ ions, and then the combination of $\mathrm{Al}$ and $\mathrm{OH}^{-}$ions resulted in $\mathrm{Al}(\mathrm{OH})_{4}{ }^{-}$, which led to corrosion. The byproduct of this

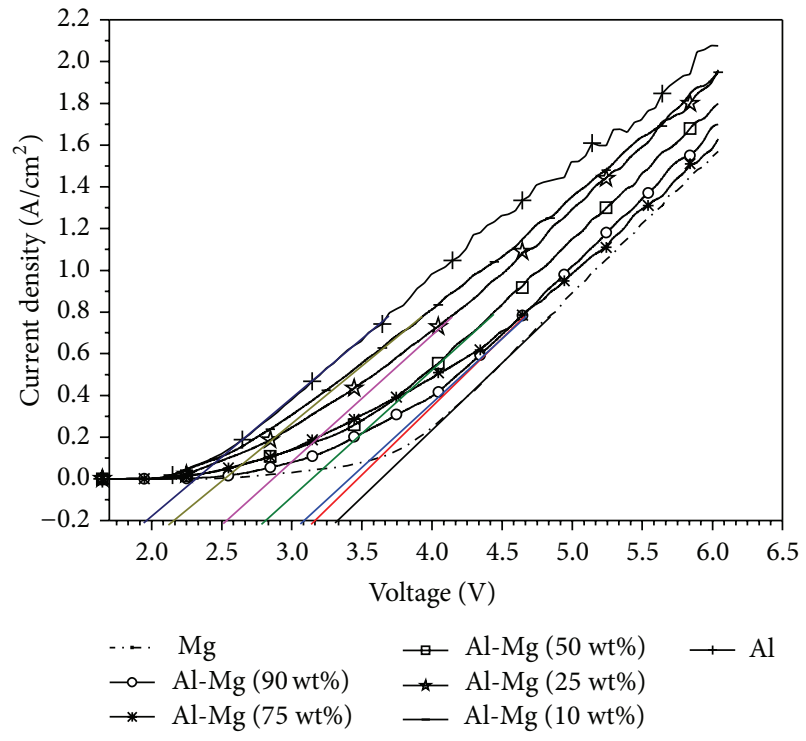

FIgURE 3: The I-V curve of seven electrodes in $30 \mathrm{wt} \% \mathrm{KOH}$ electrolyte.

chemical reaction produced hydrogen, and the product in water electrolysis was also hydrogen. If electrode consumption was not considered, the pure $\mathrm{Al}$ electrode produced an adequate amount of hydrogen. However, the Al-Mg (25 wt\%) electrode electrolyzed in the $30 \mathrm{wt} \% \mathrm{KOH}$ electrolyte for $8 \mathrm{~h}$ exhibited good corrosion resistance. If the corrosion resistance of the electrodes is considered, the Al content of the $\mathrm{Al}-\mathrm{Mg}$ alloy electrode should be equal to or less than $75 \mathrm{wt} \%$ :

$$
\begin{aligned}
& 2 \mathrm{Al}(\mathrm{s})+2 \mathrm{KOH}(\mathrm{s})+6 \mathrm{H}_{2} \mathrm{O}(\mathrm{aq}) \\
& \quad \longrightarrow 2 \mathrm{~K}^{+}(\mathrm{aq})+2 \mathrm{Al}(\mathrm{OH})_{4}{ }^{-}(\mathrm{aq})+3 \mathrm{H}_{2}(\mathrm{~g})
\end{aligned}
$$

3.2. The I-V Curve of Al-Mg Electrodes. Figure 3 shows the I-V curves of the seven electrodes in the $30 \mathrm{wt} \% \mathrm{KOH}$ electrolyte. The decomposition voltages (Table 1 , line C) were obtained by plotting a tangent on the I-V curve and intersecting the $x$-axis. The decomposition voltage of the pure $\mathrm{Al}$ and $\mathrm{Mg}$ electrodes was approximately $2.35 \mathrm{~V}$ and $3.65 \mathrm{~V}$, respectively. In summary, an electrode with a low decomposition voltage is more efficient. As shown in Figure 3, the magnitude of the current density of the electrodes is in the order of $\mathrm{Al}>$ $\mathrm{Al}-\mathrm{Mg}(10 \mathrm{wt} \%)>\mathrm{Al}-\mathrm{Mg}(25 \mathrm{wt} \%)>\mathrm{Al}-\mathrm{Mg}(50 \mathrm{wt} \%)>\mathrm{Al}-$ $\mathrm{Mg}(75 \mathrm{wt} \%)>\mathrm{Al}-\mathrm{Mg}(90 \mathrm{wt} \%)>\mathrm{Mg}$. The pure Al electrode yielded the most favorable I-V curve, and the current density decreases with the weight percentage of Al. By contrast, the $\mathrm{I}-\mathrm{V}$ curve of the pure $\mathrm{Mg}$ electrode indicated that it was 


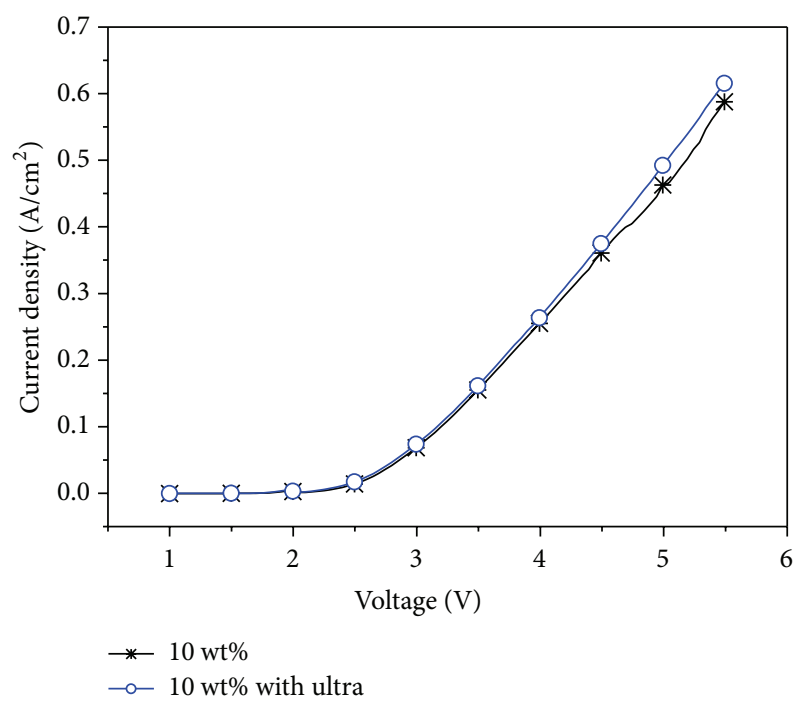

(a)

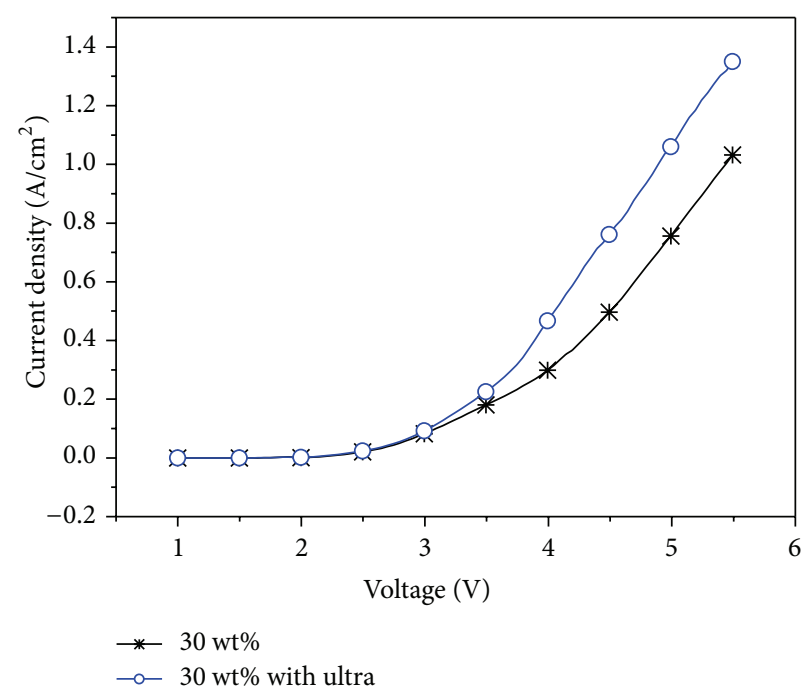

(c)

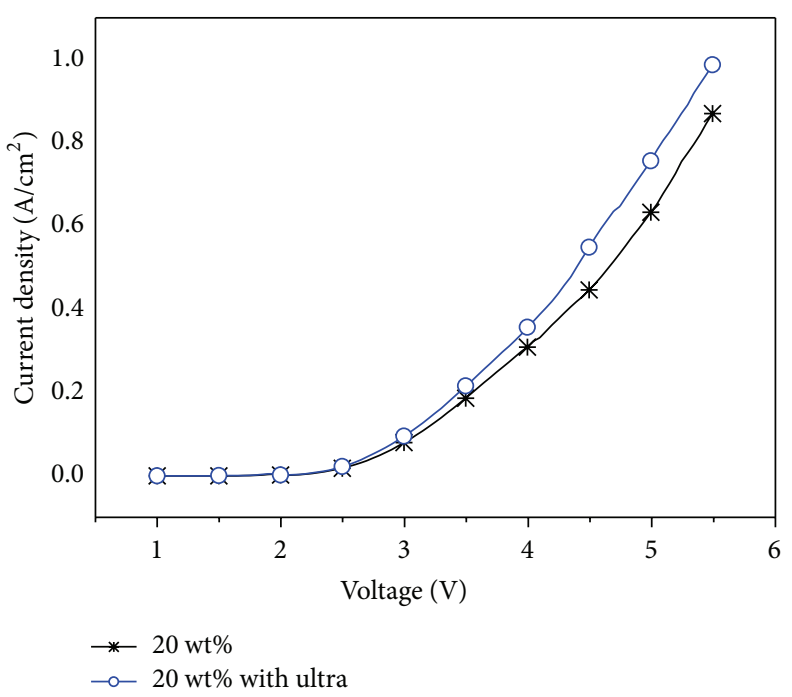

(b)

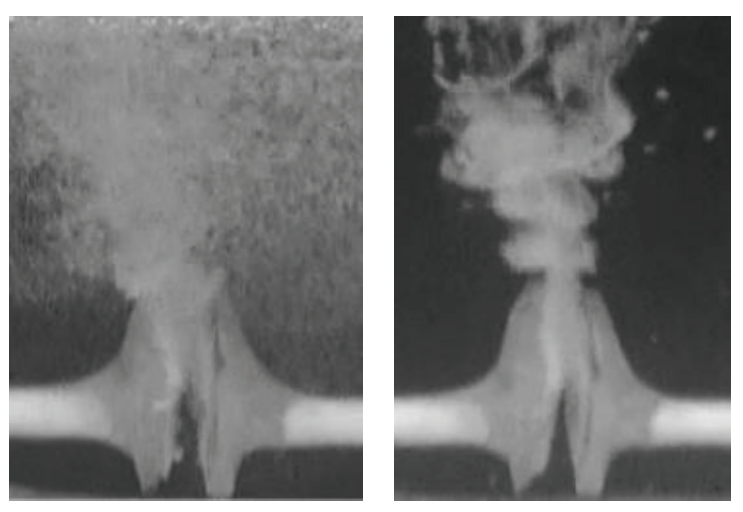

(d)

FIGURE 4: The effect of applying ultrasound on the water electrolysis for Al-Mg (25 wt\%) electrode. (a) $10 \mathrm{wt} \%$, (b) $20 \mathrm{wt} \%$, (c) $30 \mathrm{wt} \% \mathrm{KOH}$ electrolyte, (d) bubbles (without ultra), and (e) bubbles (with ultra).

the least efficient for electrolysis. In summary, the pure $\mathrm{Al}$ electrode exhibited a low decomposition voltage and optimal electrolytic efficiency, although it was susceptible to corrosion because of its high activity. Therefore, it is suitable for use as a consumable electrode. If both the corrosion property and electrolytic efficiency are considered, the preferred $\mathrm{Al}-\mathrm{Mg}$ alloy electrode would be the Al-Mg (25 wt\%) specimen. In other words, the increase in phase content of the intermetallic compound $\left(\mathrm{Al}_{12} \mathrm{Mg}_{17}\right)$ in the $\mathrm{Al}-\mathrm{Mg}$ electrodes facilitates corrosion resistance.

\subsection{The Effect of Ultrasound Application on the Efficiency of} Water Electrolysis for the Al-Mg (25wt\%) Electrode at Different Electrolyte Concentrations. An ultrasonic wave refers to a sound pressure wave at frequencies higher than $20 \mathrm{kHz}$.
Ultrasonic waves generate cyclic alternating acoustic pressures of compression and tension. When the acoustic pressure is sufficiently strong, the liquid is subjected to tensile forces during the negative cycle of the wave, and the molecules of the liquid can be pulled away from one another to form cavitation bubbles, which are transient bubbles. During the following compression cycle, the cavitation bubbles collapse violently, forming microjets and shock waves. Some of these cavitation bubbles grow rapidly under the influence of the alternating acoustic pressure and the directed diffusion of dissolved gas from the liquid, thereby forming steady bubbles. The numerous bubbles coagulate and rise to the surface of the liquid, which is called "ultrasonic degassing."

The electrolytic performance of the Al-Mg (25 wt\%) electrode was examined in three electrolyte concentrations 


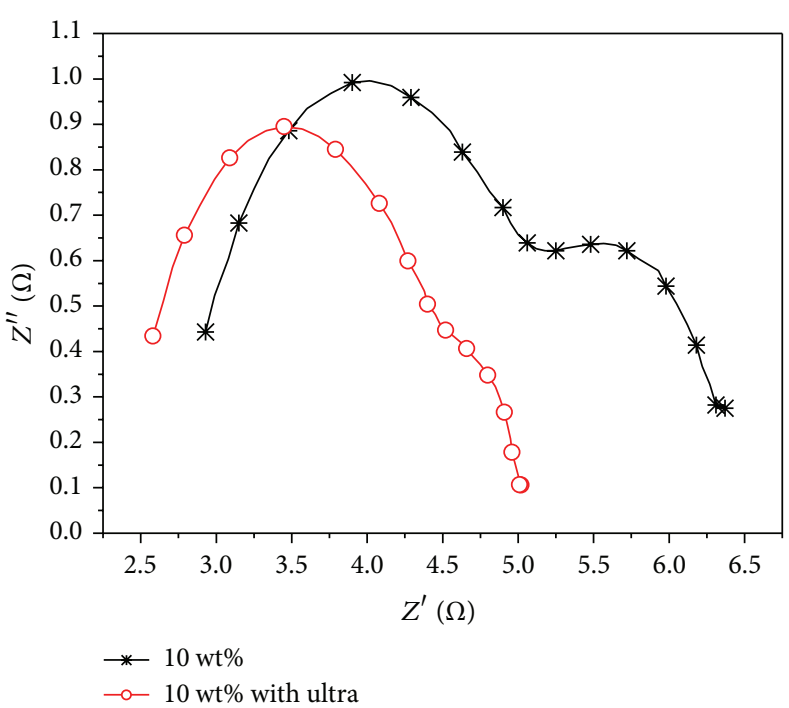

(a)

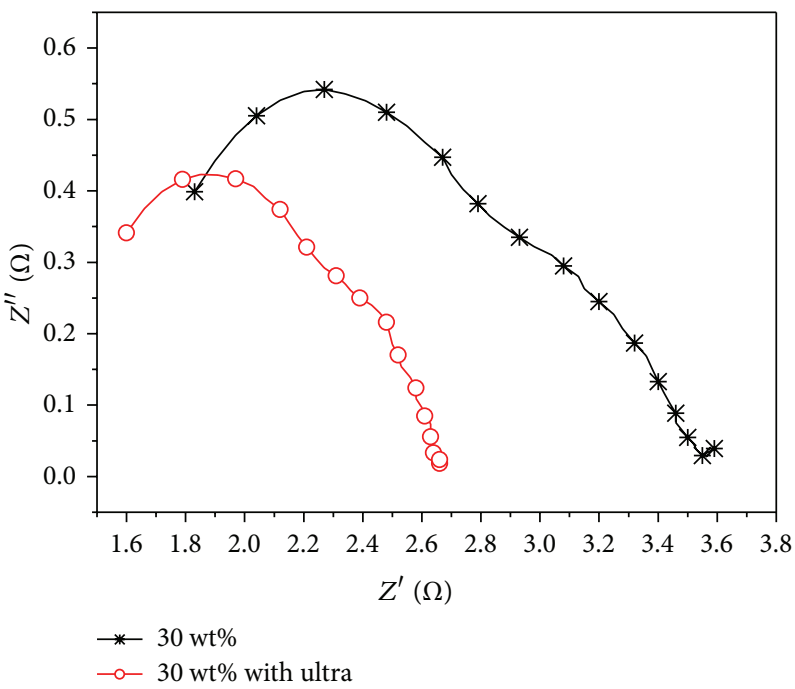

(c)

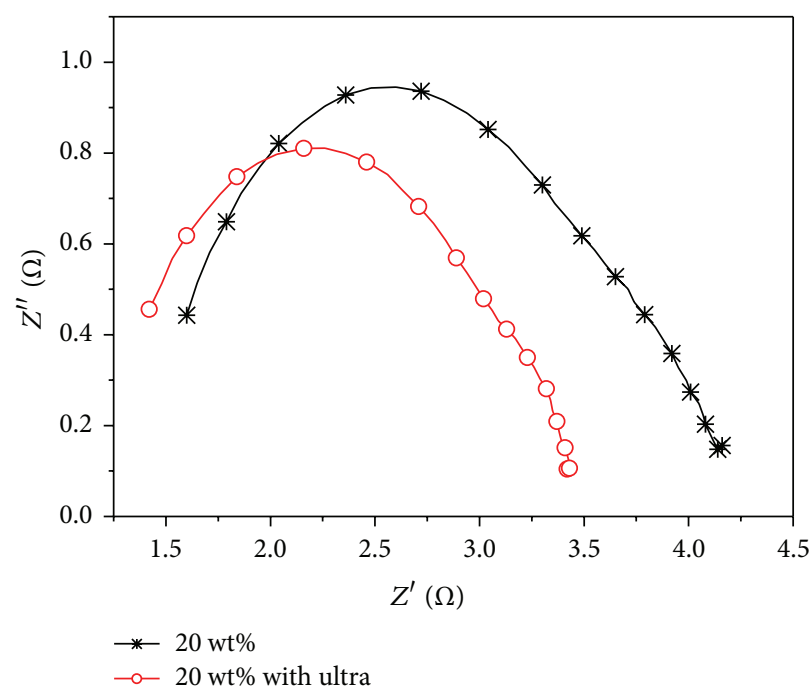

(b)

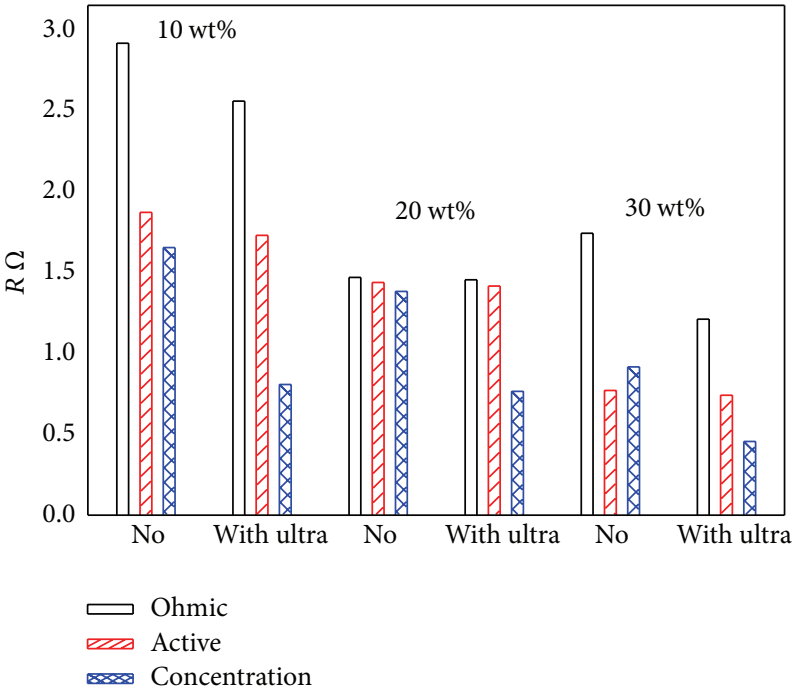

(d)

Figure 5: The Nyquist curves and polarization impedance chart at different electrolytes: (a) $10 \mathrm{wt} \%$, (b) $20 \mathrm{wt} \%$, (c) $30 \mathrm{wt} \%$, and (d) polarization impedances.

with and without ultrasound. Figures 4(a) $-4(\mathrm{c})$ show the I-V curves of water electrolysis at $5 \mathrm{~V}$. The results revealed that the current increased by $5.3 \%, 18.5 \%$, and $23.1 \%$ when the ultrasound was applied to the $10 \mathrm{wt} \%, 20 \mathrm{wt} \%$, and $30 \mathrm{wt} \%$ $\mathrm{KOH}$ electrolyte concentrations, respectively. Moreover, the camera, which was used to record the bubble behaviors in the electrolytic process, revealed bubble clusters that were created through ultrasonic forced oscillation. These phenomena are easy to understand. Introducing an ultrasound to the electrolytic cell resulted in acoustic cavitation. The creation of gas bubbles (both hydrogen and oxygen) on the electrodes accelerated, and steady bubbles were formed through direct diffusion. The bubble clusters grew rapidly and detached from the electrode surface in the sound field, effectively reducing the polarization resistance in the electrolytic cell and enhancing electrolytic efficiency.
In addition to using an I-V curve to calculate the power efficiency, a Nyquist potential impedance equivalent diagram was used to examine the relationship between the change in the polarization impedances and ultrasonic action. Figure 5 shows the EIS curves measured using the constant electric displacement FRA module with an electrode spacing of $3 \mathrm{~mm}$ and external potential of $2.8 \mathrm{~V}$. For the $10 \mathrm{wt} \%$ electrolyte condition without ultrasound, the EIS curve in Figure 5(a) shows two clearly defined semicircles. The results indicated that both the activation and concentration polarization increased because of the low electrical conductivity and poor hydration effect. Under a low-frequency condition, the electrochemical reaction time increased, and the activation and concentration polarization curves could be measured. Under the $20 \mathrm{wt} \%$ and $30 \mathrm{wt} \%$ electrolyte conditions, the low-frequency semicircles (Figures 5(b) and 5(c)) were not 
clearly defined because of the improved hydration effect. The electron and ion exchange rate between the electrodes and the electrolyte solution was high, and the overall reaction time decreased. Although the low frequencies produced longer reaction times, the polarization phenomena were minimized. In summary, applying the ultrasound to the electrolytic cell reduced polarization impedance in all cases.

Figure 5(d) shows the activation and concentration impedance at three electrolyte concentrations, which were obtained from the regression curves of the EIS curves in Figures 5(a)-5(c). Overall, the results revealed that applying ultrasonic waves to various electrolytes can effectively improve impedance. The ohm impedance, activation impedance, and concentration impedance values decreased by approximately $1 \%-30 \% \Omega, 1.5 \%-7.6 \% \Omega$, and $44 \%-51 \% \Omega$, respectively. The concentration impedance values exhibited the greatest reduction because the ultrasonic field removed the hydrogen and oxygen bubbles from the electrodes, which destroyed the diffusion layer, reduced electrode fouling, and altered the absorption and surface conditions. Consequently, the ion transmission improved, the limiting current increased, and the overpotential decreased. Furthermore, an increase in ohmic impedance was obvious for the $30 \mathrm{wt} \%$ electrolyte concentration. Under these conditions, the hydration effect of the electrolyte improved, the electron and ion exchange rate between the electrode and electrolyte was high, and the electrochemical reaction was violent. Therefore, numerous bubbles formed between the electrodes, leading to an increase in ohmic impedance. When the ultrasound was applied to the electrolysis system, the bubbles on the electrode surface were removed rapidly, and the ohmic impedance decreased from 1.8 to $1.2 \Omega$.

\section{Conclusion}

In this study, seven electrodes were prepared using a powder metallurgy method. The current density of the obtained electrodes exhibited the following characteristic: $\mathrm{Al}>\mathrm{Al}-$ $\mathrm{Mg}(10 \mathrm{wt} \%)>\mathrm{Al}-\mathrm{Mg}(25 \mathrm{wt} \%)>\mathrm{Al}-\mathrm{Mg}(50 \mathrm{wt} \%)>\mathrm{Al}-\mathrm{Mg}$ $(75 \mathrm{wt} \%)>\mathrm{Al}-\mathrm{Mg}(90 \mathrm{wt} \%)>\mathrm{Mg}$. The experimental results revealed that the electrolytic efficiency increased with the $\mathrm{Al}$ content in the electrode. However, $\mathrm{Al}$ is easily oxidized to form $\mathrm{Al}(\mathrm{OH})_{4}{ }^{-}$in a $\mathrm{KOH}$ electrolyte. Based on the anticorrosion and electrolytic efficiency of the electrodes, the Al$\mathrm{Mg}$ (25 wt\%) electrode would be the ideal candidate; in other words, the Al content of the Al-Mg alloy electrodes should be equal to or less than $75 \mathrm{wt} \%$. This electrode exhibited high corrosion resistance, and it is easy to obtain as well as economical. Furthermore, the ultrasonic wave was applied to the cells to reduce the polarization resistance. The increase in current observed for various electrolyte concentrations revealed the following tendency: $30 \mathrm{wt} \% \mathrm{KOH}>20 \mathrm{wt} \%$ $\mathrm{KOH}>10 \mathrm{wt} \% \mathrm{KOH}$. In the $30 \mathrm{wt} \% \mathrm{KOH}$, the optimal current increased by $23.1 \%$. The EIS curves, measured using the FRA module and the regression curves, indicated an effective improvement in polarization impedance between the electrodes under ultrasonic vibration. The concentration polarization in the $30 \mathrm{wt} \% \mathrm{KOH}$ under ultrasonic conditions decreased to $44 \%-51 \% \Omega$ during electrolysis.

\section{Conflict of Interests}

The authors declare that there is no conflict of interests regarding the publication of this paper.

\section{Acknowledgments}

The authors are grateful to the three anonymous referees for their helpful comments on an earlier version of this paper.

\section{References}

[1] K. Mazloomi, N. B. Sulaiman, and H. Moayedi, "Electrical efficiency of electrolytic hydrogen production," International Journal of Electrochemical Science, vol. 7, no. 4, pp. 3314-3326, 2012.

[2] N. Nagai, M. Takeuchi, T. Kimura, and T. Oka, "Existence of optimum space between electrodes on hydrogen production by water electrolysis," International Journal of Hydrogen Energy, vol. 28, no. 1, pp. 35-41, 2003.

[3] R. F. de Souza, J. C. Padilha, R. S. Gonçalves, M. O. de Souza, and J. Rault-Berthelot, "Electrochemical hydrogen production from water electrolysis using ionic liquid as electrolytes: towards the best device," Journal of Power Sources, vol. 164, no. 2, pp. 792798, 2007.

[4] R. F. de Souza, J. C. Padilha, R. S. Gonçalves, and J. RaultBerthelot, "Dialkylimidazolium ionic liquids as electrolytes for hydrogen production from water electrolysis," Electrochemistry Communications, vol. 8, no. 2, pp. 211-216, 2006.

[5] S. Licht, B. Wang, S. Mukerji, T. Soga, M. Umeno, and H. Tributsch, "Over 18\% solar energy conversion to generation of hydrogen fuel; theory and experiment for efficient solar water splitting," International Journal of Hydrogen Energy, vol. 26, no. 7, pp. 653-659, 2001.

[6] P. K. Dubey, A. S. K. Sinha, S. Talapatra, N. Koratkar, P. M. Ajayan, and O. N. Srivastava, "Hydrogen generation by water electrolysis using carbon nanotube anode," International Journal of Hydrogen Energy, vol. 35, no. 9, pp. 3945-3950, 2010.

[7] V. M. Nikolic, G. S. Tasic, A. D. Maksic, D. P. Saponjic, S. M. Miulovic, and M. P. Marceta Kaninski, "Raising efficiency of hydrogen generation from alkaline water electrolysis-energy saving," International Journal of Hydrogen Energy, vol. 35, no. 22, pp. 12369-12373, 2010.

[8] M.-Y. Lin, L.-W. Hourng, and C.-W. Kuo, "The effect of magnetic force on hydrogen production efficiency in water electrolysis," International Journal of Hydrogen Energy, vol. 37, no. 2, pp. 13111320, 2012.

[9] H. Matsushima, A. Bund, W. Plieth, S. Kikuchi, and Y. Fukunaka, "Copper electrodeposition in a magnetic field," Electrochimica Acta, vol. 53, no. 1, pp. 161-166, 2007.

[10] C.-Y. Hung, S.-D. Li, C.-C. Wang, and C.-Y. Chen, "Influences of a bipolar membrane and an ultrasonic field on alkaline water electrolysis," Journal of Membrane Science, vol. 389, pp. 197-204, 2012.

[11] L. de Silva Muñoz, A. Bergel, D. Féron, and R. Basséguy, "Hydrogen production by electrolysis of a phosphate solution on a stainless steel cathode," International Journal of Hydrogen Energy, vol. 35, no. 16, pp. 8561-8568, 2010. 
[12] A. Bai and C.-C. Hu, "Composition controlling of Co-Ni and $\mathrm{Fe}$-Co alloys using pulse-reverse electroplating through means of experimental strategies," Electrochimica Acta, vol. 50, no. 6, pp. 1335-1345, 2005.

[13] E. A. Neppiras, “Acoustic cavitation: an introduction," Ultrasonics, vol. 22, no. 1, pp. 25-28, 1984.

[14] R. E. Apfel, “Acoustic cavitation inception," Ultrasonics, vol. 22, no. 4, pp. 167-173, 1984.

[15] E. A. Neppiras, "Acoustic cavitation thresholds and cyclic processes," Ultrasonics, vol. 18, no. 5, pp. 201-209, 1980.

[16] K. S. Suslick, "The chemical effects of ultrasound," Scientific American, vol. 80, pp. 80-86, 1989.

[17] G. I. Eskin, "Cavitation mechanism of ultrasonic melt degassing," Ultrasonics Sonochemistry, vol. 2, no. 2, pp. S137-S141, 1995. 

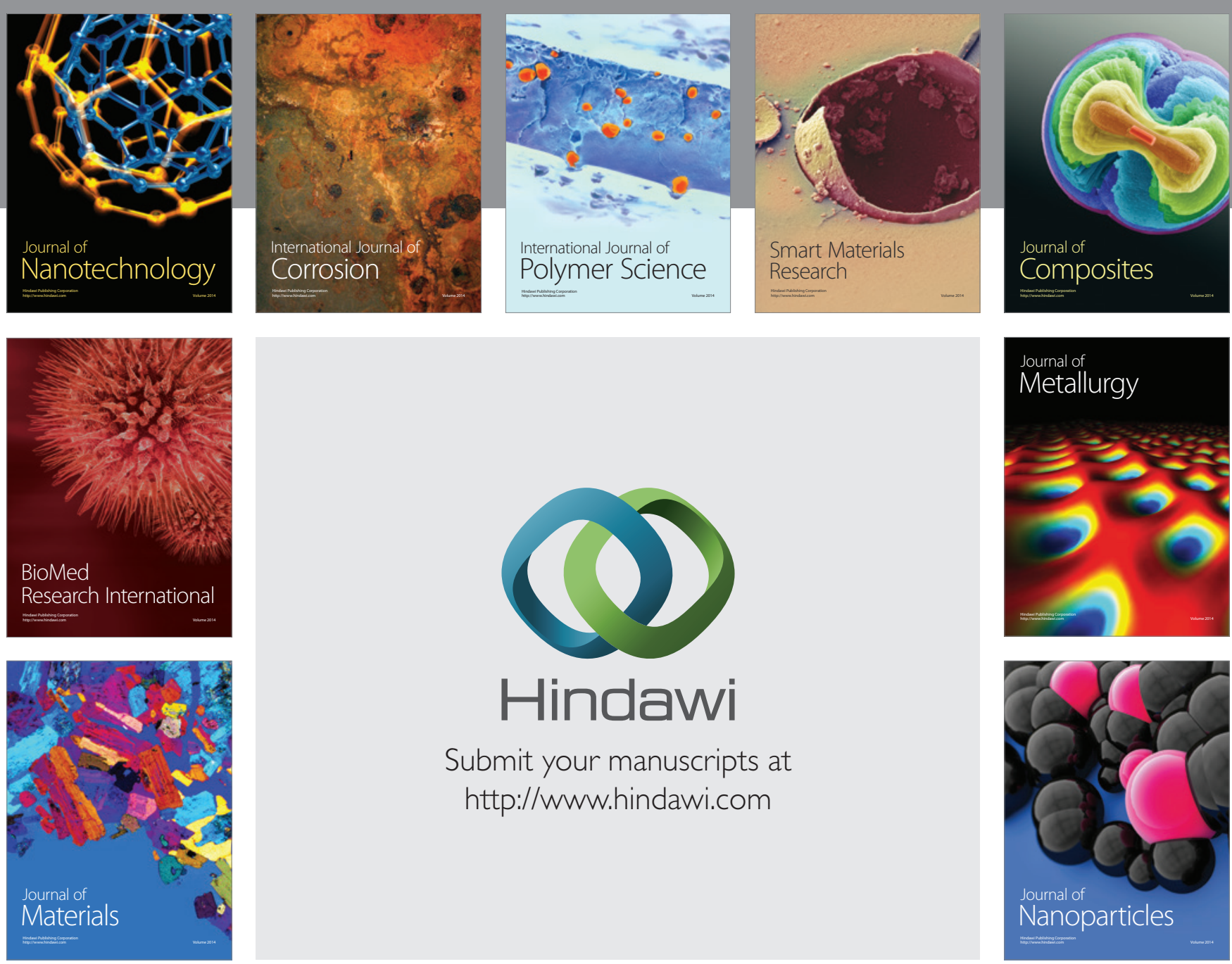

Submit your manuscripts at http://www.hindawi.com
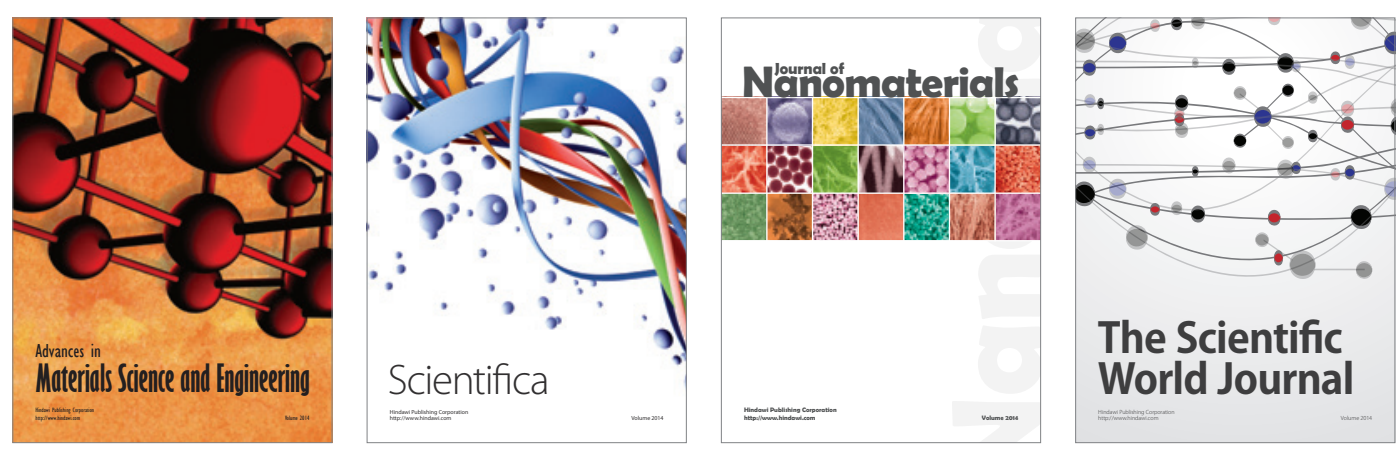

\section{The Scientific World Journal}
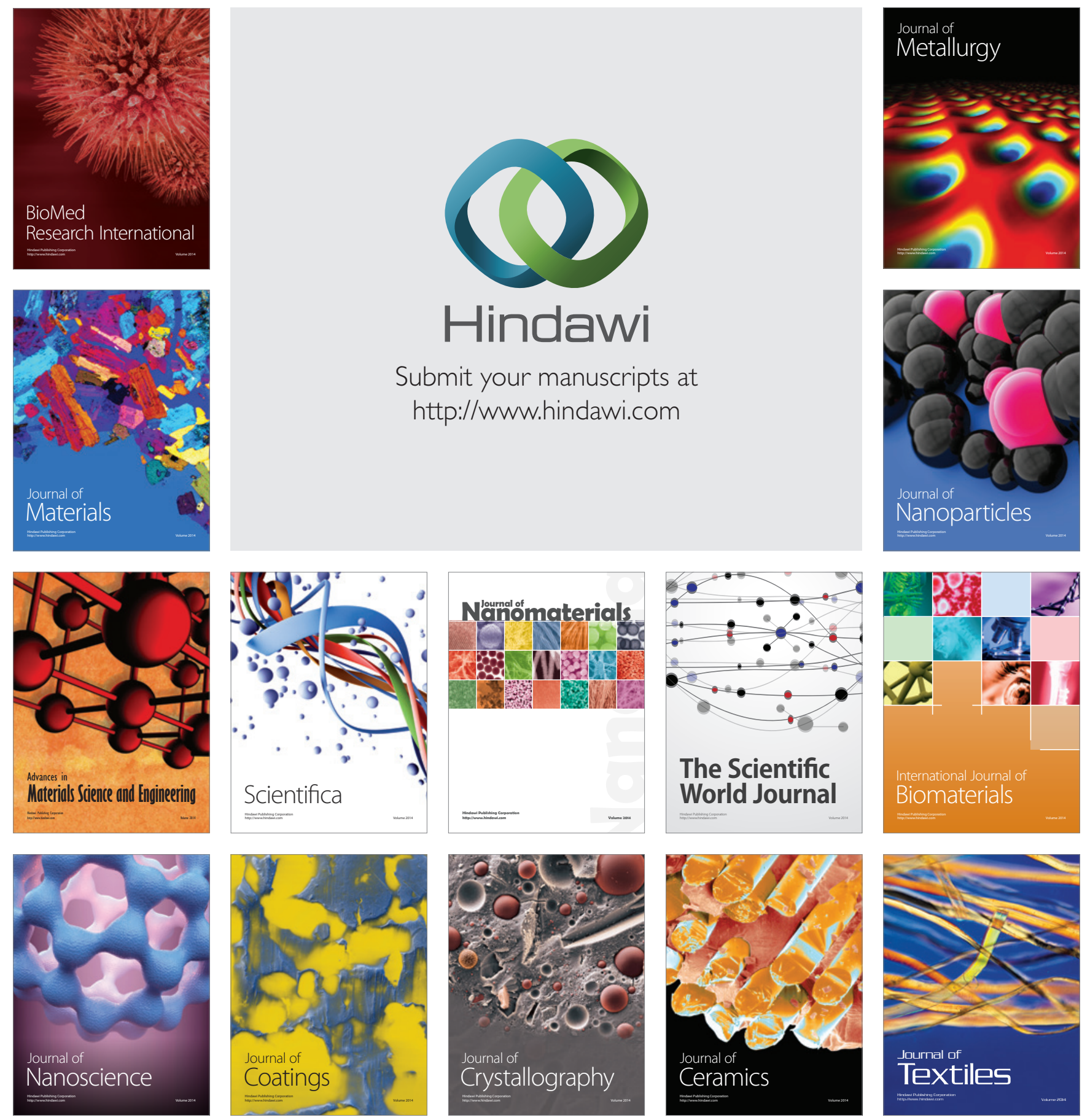